\title{
Angular Pregnancy Presenting as Cornual Ectopic Pregnancy
}

Biswas $\mathrm{SP}^{1}$, Halder $\mathrm{S}^{2}$, Shirin $\mathrm{FB}^{3}$.

\begin{abstract}
Angular pregnancy is a rare obstetric complication that can be life threatening. In this situation, gestational sac is implanted in the lateral angle of the uterine cavity, medial to the uterotubal junction and round ligament. Angular pregnancy is distinguished from interstitial pregnancy by anatomically, where embryo is implanted lateral to round ligament. The report presented here describes a case of angular pregnancy that was suspected by ultrasound and confirmed during surgery. Laparoscopy can be useful for guiding dilatation \& curettage in angular pregnancy and may circumvent the need for invasive surgery or hysterectomy. It has an impact on future fertility.
\end{abstract}

\section{Introduction}

Angular pregnancy is a rare condition in which gestational sac is implanted in the lateral angle of the uterine cavity ${ }^{1}$. Despite the similarity in terminology, an angular pregnancy is distinct from a cornual pregnancy one; although it may occur in an abnormal uterus both congenital and acquired, the pregnancy is always intrauterine and located medial to the insertion of fallopian tube ${ }^{2}$. An interstitial ectopic pregnancy develops in the uterine portion of the fallopian tube. But angular pregnancy develops in the interstitial portion of the fallopian tube and then grows into the adjacent uterine cavity. Thus an angular pregnancy is a continuation of an interstitial pregnancy ${ }^{3}$. While interstitial pregnancies account for only $2-4 \%$ of all ectopic gestations ${ }^{4,5,6}$. They cause a disproportionately high incidence of haemoperitoneum and shock and the mortality rate is approximately twice than that of other types of ectopic pregnancies ${ }^{7}$. One case of unruptured angular ectopic pregnancy is being reported here.

1. Corresponding Author : Dr. Sankar Prosad Biswas Assistant Professor

Department of Obstatic \& Gynae

Khulna Medical College,Khulna.

Email: drsankar2010@gmail.com

2. Dr. Suravi Halder

Assiatant Registrar

Department of Obstatic \& Gynae

Khulna Medical College,Khulna.

3. Dr. Feroja Banu Shirin

Assistant Registrar

Department of Obstatic \& Gynae

Khulna Medical College,Khulna.

\section{Case Report}

A 22 -years old women gravida 3, para $1+1$ (MR), whose last normal menstrual period was $26^{\text {th }}$ December,2010 was admitted on $5^{\text {th }}$ April, 2011 in Gynaecology department of Khulna Medical College Hospital, Khulna with history of sharp non radiating right lower abdominal pain of mild degree for 10 days prior to admission. There was per vaginal bleeding at the onset of pain which was scanty in amount $\&$ dark in color and subsided within 12-15 hours. She also noticed a lump in lower abdomen for the last 20 days before admission. She had no complains of dysuria, frequency or diarrhea. Previous operation was included only menstrual regulation on $10^{\text {th }}$ December, 2008.

Physical examination revealed normal temperature, pulse \& blood pressure but mild anaemia. Per abdominal examination exhibited a clearly defined soft, tender, rounded mobile mass about $3 \times 3 \mathrm{~cm}$ in hypogastric region. On per vaginal examination, there was no bleeding, uterus was just bulky \& a soft mass was felt through the right fornix which was adherent to right horn of uterus. The leucocytes count was11,500/cu mm with normal differential count, Haemoglobin determination was $10.1 \mathrm{gm} / \mathrm{dl}$. Pregnancy test was reported positive. Transabdominal ultrasound revealed cornual ectopic pregnancy with living fetus of about 14 weeks duration. A decision of laparotomy was taken and done on $6^{\text {th }}$ April, 2011 under general anaesthesia. On opening the abdomen, a mass was seen which was adjacent to the right horn of the uterus and just medial and anterior to the insertion of the right tube and right round ligament. Removal of right horn \& right fallopian was done. Uterus was repaired accordingly and abdomen was closed layer by layer. Peroperative bleeding was minimum and no blood transfusion was given. Her post operative period was uneven full and she was discharged on $12^{\text {th }}$ April, 2011 after full recovery.

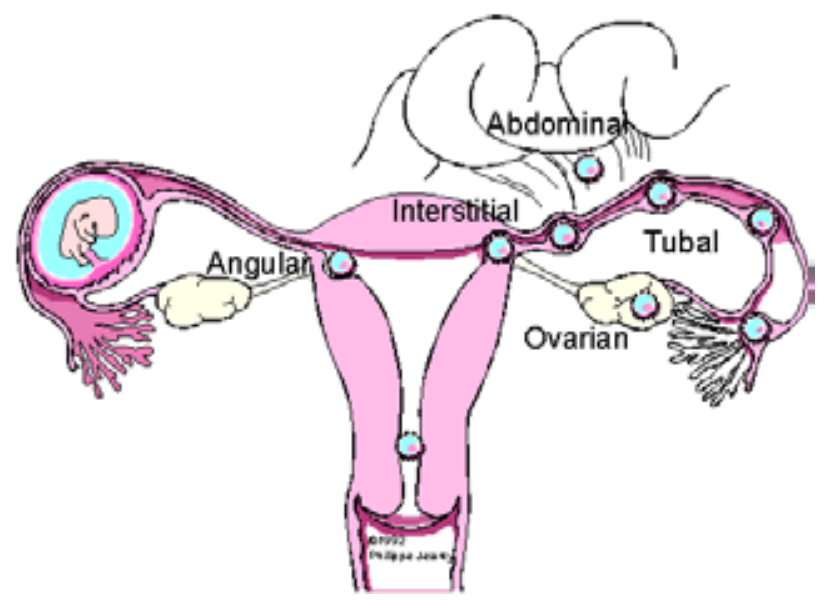

Fig. I Classification of tubal ectopic pregnancies 


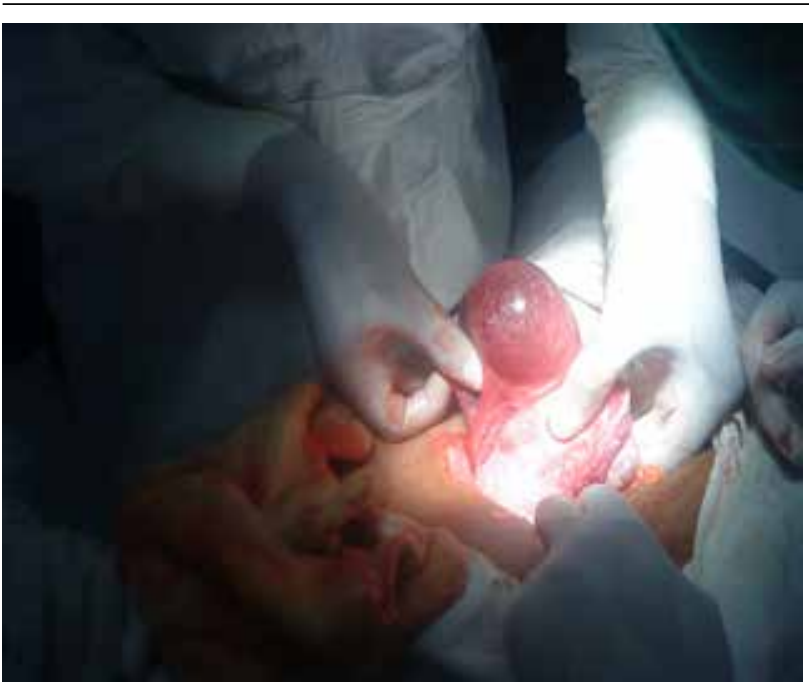

Fig. II: Angular gestational sac

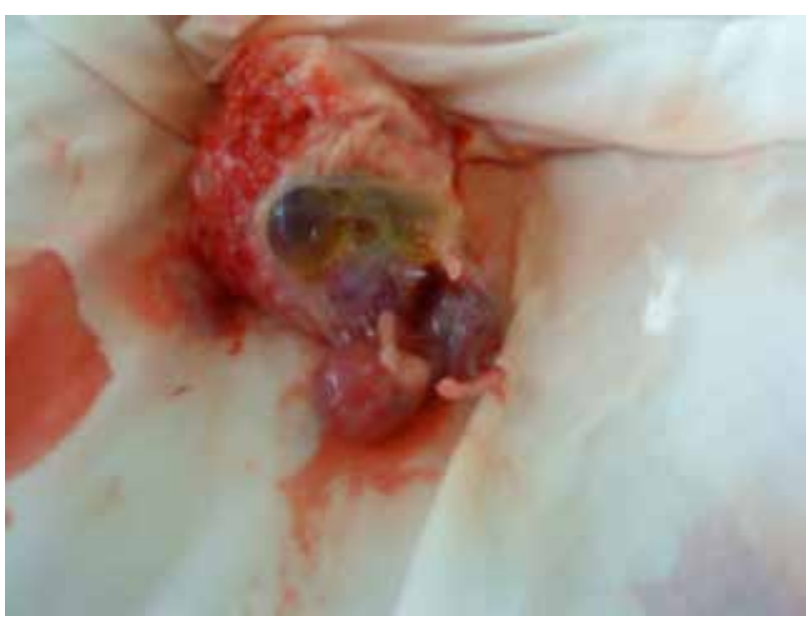

Fig. III Excise gestational sac with living foetus

\section{Discussion}

Despite an abundant continuing literature on the subject of ectopic gestation, there has been little discussion concerning angular pregnancy. Possibly contributory to the dearth of reported cases may be lack of recognition of this unusual ectopic variant and as has been shown the possibility of spontaneous regression exists ${ }^{8}$. One of the most through discussion of angular pregnancy is that of Munro Kerr, who defines this entity as a 'gestation in which the ovum becomes implanted in the angle or cornu of the uterus either directly over the tubal opening or more probably, in the interstitial portion of the tube immediately external to that opening'. The critical differential feature is that the fertilized ovum of an interstitial pregnancy essentially develops in the uterine wall (in substantia uteri) whereas in an angular pregnancy, it develops towards the uterine cavity9. Anatomically the angular pregnancy is implanted medial to the round ligament ${ }^{10}$.
The maternal mortality rate is 1 per 1000 and this is twice the mortality rate of tubal ectopic pregnancies. The portion of uterine cavity medial to the cornu is a highly vascularised muscular site that offers more support and distensibility to the embryo than any other portion of the fallopian tube. These anatomical features allow the gestation to advance much further into its development than when the embryo implants in other portions of the fallopian tube ${ }^{11}$.Our reported case also advanced in second trimester. The prognosis for the fetus is poor if pregnancy progress. Few angular pregnancies develop into a normal uterus will rupture, but many of these pregnancies abort. Approximately a quarter result into live birth. A third will develop into a cornual pregnancy and end up by uterine rupture ${ }^{10}$. If it develops into cornual ectopic pregnancy, there is high risk of rupture at all gestational age, up to and including full term with surgical delivery ${ }^{5}$. In our case gestational age was 14 weeks and foetus was alive with intact sac.

Angular pregnancy usually presents as severely painful, tender, lateral sacculation of the uterus in the twelfth to twentieth weeks of gestation. Vaginal bleeding may or may not be present ${ }^{12}$. Abdominal pain, vaginal bleeding, haemorragic shock may cause relatively high mortality rate. In our case adnexal mass was severely tender who present at her $14^{\text {th }}$ weeks of gestation but slight vaginal bleeding was present.

Early diagnosis is important. Today it is facilitated by the use of sonography and quantitative assay of human chorionic gonadotrophin. In pregnant patient sonography is the primary method to make the diagnosis, even when the patients have no symptoms. The paucity of myometrium around the gestational sac is diagnostic of interstitial pregnancy, while, in contrast, the angular pregnancy has at least $5 \mathrm{~mm}$ of myometrium on all of its sides ${ }^{13}$. Ultrasound criteria for the diagnosis include an empty uterine cavity, a gestational sac separate from the uterine cavity, and a myometrial thinning of less than 5 $\mathrm{mm}$ around the gestational sac; typically the interstitial line sign -an echogenic line from the endometrial cavity to the corner next to the gestational mass is seen ${ }^{14}$. MRI can be used particularly when it is important to distinguish between an angular pregnancy and interstitial pregnancy. Cases that are not diagnosed until surgery show an asymmetrical bulge in the corner of the uterus ${ }^{15}$. In our case, angular pregnancy was diagnosed during surgery.

The overall incidence of ectopic pregnancy increased during the mid twentieth century, plateauing at approximately almost 20 per 1000 pregnancies in early $1990 \mathrm{~s}^{16}$. The rising incidence is strongly associated with an increased incidence of pelvic inflammatory disease ${ }^{17}$. So timely diagnose and appropriate management is important to reduce maternal mortality \& morbidity. 
The treatment is carried out according to the clinical state: endometrial curettage under laparoscopic control, removal of uterine horn with the tube on the same side or even hysterectomy ${ }^{18}$.

Patient with an ectopic pregnancy are generally at a higher risk for recurrence. However there are no specific data for patient with an angular pregnancy. When a new pregnancy is diagnosed, it is important to monitor the pregnancy by transvaginal

sonography to assure that it is properly located and that the surgically repaired area remains intact. Caesarean delivery is recommended to avoid uterine rupture during labour ${ }^{19}$.

Angular pregnancy may casue life threatening complication. It may also affect further pregnancy. So, early diagnosis and appropriate time management may save the life and obstetric outcome.

\section{References}

1. Kwon JY, Hwang SI, Shin JE, Yoon WS, Shin JC, Park IY. Two cases of angular pregnancy, Complicated by preterm labour and placental abruption at mid-pregnancy. Journal of obsterics and Gynaecology Research (e), Japan Society of Obstetrics and Gynaecolgy 2011; 37: 958-962.

2. Smith,H.J., Hanken,H., Brundelet,P.J. Ultrasound diagnosis of interstitial

pregnancy. Acta Obstetrica,Ggnecologica Scandinavia 1981;60: 413-415.

3. Baldawa PS, Chaudhari HK. Angular ectopic pregnancy presenting as rupture of lateral wall of the uterus. J Hum Reprod Sci 2008; 1: 33-4.

4. Bond AL, Grifo JA, Chervenak PA, Kramers EE, Harris MA. Term interstitial

pregnancy with uterine torsion: Sonographic, Pathologic and Clinical findings.Obstet Gynecol 1989;73:857-9.

5. Maliha WE, Gonela P, Degnan EJ. Ruptured interstitial pregnancy presenting as an intrauterine pregnancy by ultrasound. Ann Emerg Med 1991; 20:910-2.

6. Coady DI, Synder JR, Golstein SR, Subramanyam BR. Ultrasound diagnosis of interstitial pregnancy. NY State J Med 1985; 85: 655-6.
7. Jafri SZ, Loginsky SI, Bouffard JA, Salis JE. Sonographic detection of interstitial pregnancy .J clin ultrasound $1987 ; 15: 253-7$.

8. McELIN T.W." Ectopic pregnancy". In Textbook of Obstetrics and Gynaecology, DANFORTH, D.N. Ed, Hocber, Newyork, 1966; 343-344.

9. MOIR, J.C. "Angular pregnacy”. In operative obstetrics, $7^{\text {th }}$ ed, KEER, J.M.M, and MOIR, J.C. Balliere, Tindall \& Cox, London, 1964; 733-798.

10. Jansen R.P.S, Elliott PM. Angular intrauterine pregnancy. Obstetrics \& Gynaecology 1981; 58:167-175.

11. Kerr LM, Anderson DF. Angular pregnancy; a clinical entity. Br Med J 1934; 1: 1113-4.

12. WOOLAM GL,PRATT JH, WILLSON RB. Uterine rupture following tubal implantation. Obstet Gynecol 1967; 29:415.

13. Donbilet P,Benson CB. Atlas of ultrasound in obstetrics and Gynaecology.

Philadelphia: Leppin Cott Williams \& Wilkins ,2003;ISBN 0781736331

14. AcKerman TE, Levi CS, Dashefsky SM, Holt SC, Lindsay DJ. "Interstitial line; Sonographic finding in interstitial (cornual) ectopic pregnancy". Radiology 1993;189(1):83-87.

15. Moawad NS, Mahajan ST, Moniz MH, Taylor SE, Hurd WW. "Current diagnosis and treatment of interstitial pregnancy".American Journal of Obstetrics \& Gynaecology 2010;202(1):15-29.

16. Centers for Disease Control and prevention(CDC). Ectopic pregnancy- United States.1990-1992.MMWR Morb Mortal wkly Rep 1995; 44:46.

17. Kamwendo F, Forstin 1, Danielsson D. Epidemiology of ectopic pregnancy during a 28 years period and the role pelvic inflamatory disease. Sex Transm Infect 2000; 76:28

18. Cochand- Priollet B, Gnerin D,Charbonnier JY, Dubost C, Lecharpentier Y. Ruptured angular pregnancy in the $16^{\text {th }}$ week: A propos of a case. J Gynaecol Obstet Biol Reprod (paris) 1984; 13(7):808-11

19. Loret de Mola JR, Austin CM, Judge NE, Assel BG, Peskin B, Goldfarb JM. "Cornual heterotrophic pregnancy and cornual resection after in vitro fertilization / embryo transfer : a report of two cases". J Reprod Med 1995; 40(8):606-610. PMID 7473461 